Notas y Comentarios

\title{
Características étnico-raciales y desigualdad de oportunidades económicas en México
}

\section{Ethnic-racial characteristics and unequal economic opportunities in Mexico}

\author{
Patricio Solís* \\ Braulio Güémez**
}

\begin{abstract}
Resumen
El presente trabajo examina la asociación entre las características étnico-raciales y los resultados económicos en México. A partir de datos del Módulo de Movilidad Social Intergeneracional 2016, levantado por el INEGI (2017) como parte de la Encuesta Nacional de los Hogares, nuestros hallazgos indican que todas las características étnico-raciales estudiadas (autoadscripción, lengua indígena y tono de piel) se asocian de manera estadísticamente significativa con los destinos económicos de las personas, siendo la dimensión lingüistica aquella que sobresale por tener los efectos de mayor magnitud. La autoadscripción étnico-racial, y en particular la adscripción mestiza o blanca, en contraste con la indígena, tiene un efecto menor que el observado para la dimensión lingüistica, pero mayor con respecto al tono de piel. Encontramos que estas asociaciones son estadísticamente significativas incluso controlando por los orígenes socioeconómicos, lo que sugiere que las inequidades económicas son explicadas tanto por una acumulación histórica de desventajas como por la persistencia de prácticas de racismo y discriminación en el presente.
\end{abstract}

Palabras clave: desigualdad social, tono de piel, racismo, indígenas.

* El Colegio de México, A.C., Centro de Estudios Sociológicos. Dirección: Carretera Picacho Ajusco 20, Ampliación Fuentes del Pedregal, 14110, Ciudad de México, México. Correo: psolis@colmex.mx ORCID: https://orcid.org/0000-0002-9470-8362

** El Colegio de México, A.C. Correo: bguemez@colmex.mx ORCID: https://orcid. org/0000-0001-6774-5013

Nota de los autores: Una parte de este documento se apoya en el informe "Por mi raza hablará la desigualdad. El impacto de las características étnico-raciales en la desigualdad de oportunidades en México", publicado por Oxfam México en julio de 2019. Disponible en https://www.oxfammexico.org/sites/default/files/Por\%20mi\%20raza $\% 20$ hablara\%201a $\% 20$ desigualdad_0.pdf 


\begin{abstract}
This article examines the association between ethnic-racial characteristics and economic results in Mexico. Based on data from the 2016 Intergenerational Social Mobility Module, compiled by INEGI (2017) as part of the National Household Survey, our findings indicate that all the ethnic-racial characteristics studied (self-classification, indigenous language and skin tone) are associated in a statistically significant way with people's economic destinies, with the linguistic dimension having the largest effect. Ethnic-racial self-classification, particularly mestizo or white rather than indigenous, has a smaller effect than that observed for the linguistic dimension, yet a greater one than skin tone. We find that these associations are statistically significant even when socioeconomic origins are controlled for, suggesting that economic inequalities can be explained by both the historical accumulation of disadvantages and the persistence of racist and discriminatory practices in the present.
\end{abstract}

Keywords: social inequality, skin tone, racism, indigenous people.

\title{
Introducción
}

Por mucho tiempo ha predominado entre los mexicanos la idea de que México no es una sociedad racista. Se reconoce la situación de desventaja social de los pueblos indígenas, pero ésta se suele explicar por la falta de desarrollo socioeconómico, el aislamiento geográfico o el "atraso cultural", y no por un orden social que les impone privaciones sistemáticas en virtud de su posición étnico-racial. Es común escuchar anécdotas de maltrato hacia personas de piel morena, pero éstas se interpretan como casos aislados, anecdóticos, no como prácticas sistemáticas de discriminación. Se idealiza un México integrado étnica y racialmente a través del mestizaje, cuando esta "integración" oculta una enorme diversidad étnica y de rasgos físicos racializados, con importantes implicaciones en la reproducción de la desigualdad social.

Esta percepción ha comenzado a cambiar en los últimos años, a partir de una serie de acontecimientos sociales y políticos que han dirigido la mirada hacia la pluralidad étnico-racial de México y la situación de privación de derechos en la que se encuentran las personas pertenecientes a pueblos indígenas y afrodescendientes. ${ }^{1}$ En el ámbito de la investigación académica, se ha desarrollado una nueva ola de estudios que analizan los efectos es-

\footnotetext{
${ }^{1}$ Entre estos acontecimientos destaca el levantamiento indígena zapatista de 1994 en Chiapas, así como las luchas que le siguieron por el reconocimiento y los derechos constitucionales de los pueblos indígenas y afromexicanos, que se han reflejado en una serie de cambios constitucionales. En el más reciente de ellos les otorga reconocimiento constitucional a los pueblos afromexicanos.
} 
tructurales de las características étnico-raciales en la desigualdad social. En particular, se ha enfatizado el análisis de las desigualdades asociadas al tono de piel (Telles, Flores y Urrea-Giraldo, 2015; Trejo y Altamirano, 2016; Villarreal, 2010), que se suma a los estudios sobre las desventajas sociales de los hablantes de lenguas indígenas (González de Alba, 2017; Ramírez, 2005; Villarreal, 2014), de las personas que se autoadscriben como indígenas, y de los pueblos afrodescendientes (Barbary, 2015; Telles, 2014; Telles y Torche, 2018; Villarreal y Bailey, 2019).

En este trabajo buscamos realizar aportaciones a este campo de investigación mediante un análisis macrosocial de los efectos de las características étnico-raciales en las oportunidades económicas. Adoptamos un enfoque de desigualdad de oportunidades (Bonilla-Silva, 1997; Breen y Jonsson, 2005; Breen y Rottman, 1995; Feagin y Elias, 2013), que nos lleva a conceptualizar las características étnico-raciales como rasgos adscriptivos que forman parte del conjunto de circunstancias sociales de origen que afectan las probabilidades de las personas para acceder a oportunidades de vida. Partimos de la revisión de los estudios recientes para identificar cuatro áreas específicas en las que nuestro trabajo realiza aportes originales: a) la adopción de un enfoque multidimensional de las características étnico-raciales; $b$ ) la inclusión de un conjunto más completo de características socioeconómicas de origen, que permite identificar con mayor claridad la interrelación entre los efectos socioeconómicos y los étnico-raciales; c) la distinción conceptual y empírica entre los efectos de la acumulación histórica de las desventajas asociadas a las características étnico-raciales y los efectos de la persistencia en el presente de la discriminación étnico-racial; y $d$ ) la identificación de los efectos mediadores de la escolaridad en la asociación entre las características étnico-raciales y los logros económicos de las personas.

Además de esta introducción, el trabajo se organiza en cuatro secciones. En la siguiente discutimos los antecedentes de investigación más relevantes, así como nuestra aproximación al enfoque de desigualdad de oportunidades étnico-raciales. La sección comienza con una serie de preguntas específicas que buscamos responder en el trabajo. Le sigue una sección metodológica, en la que describimos la fuente de datos, las variables utilizadas en el estudio y los modelos estadísticos aplicados. Posteriormente analizamos los resultados empíricos, partiendo de una breve revisión descriptiva y terminando con los modelos estadísticos. Por último, en la sección de discusión y conclusiones valoramos los resultados empíricos y evaluamos sus implicaciones para la discusión contemporánea sobre etnia, raza y desigualdad social en México. 


\section{Desigualdad de oportunidades y características étnico-raciales}

A pesar de que México se caracteriza por la persistencia histórica de altos niveles de desigualdad, hasta hace un par de décadas los estudios sobre desigualdad social se concentraban fundamentalmente en la medición de la desigualdad distributiva, es decir, del grado de concentración en la distribución de activos o recursos (principalmente el ingreso) entre los hogares o las personas en un momento dado en el tiempo. En las últimas dos décadas esta situación ha cambiado gradualmente, a partir de una nueva ola de estudios sobre movilidad social (Cortés y Escobar Latapí, 2005; Delajara y Graña, 2017; Serrano Espinosa y Torche, 2010; Solís y Boado, 2016; Torche, 2014). Estos estudios han enfatizado que, para entender la persistencia histórica de la desigualdad social en México, es fundamental estudiar no sólo la desigualdad distributiva, sino también la desigualdad de oportunidades; es decir, la relación entre las características adscriptivas o circunstancias sociales de origen de las personas y sus probabilidades de acceder a oportunidades de vida (Breen y Jonsson, 2005; Breen y Rottman, 1995; Solís y Boado, 2016; Fox, Torche y Waldfogel, 2017; Tilly, 1999).

La mayoría de los estudios sobre movilidad social intergeneracional en México se han orientado al análisis de una dimensión específica de la movilidad. Por sus diferentes tradiciones disciplinarias, los sociólogos se han concentrado en el análisis de la movilidad de clase (ocupacional), mientras que los economistas en la movilidad de riqueza o ingresos (Solís, 2018). Una de las desventajas de este enfoque compartimentalizado de la movilidad social es que ignora el carácter multidimensional de las circunstancias sociales de origen: el origen social de las personas se define por la combinación de las características de su familia originaria y de otras circunstancias sociales relevantes (clase social de origen, nivel socioeconómico de origen, género, lugar de socialización, etc.). Al reducir este espacio multidimensional a una dimensión específica, se corre el riesgo de subestimar el grado de desigualdad de oportunidades, al tiempo que se pierde la posibilidad de evaluar esta disparidad desde una perspectiva interseccional.

Por otra parte, quizás por su énfasis casi exclusivo en las dimensiones ocupacional y económica, los estudios sobre movilidad social y desigualdad de oportunidades en México no han puesto suficiente atención a las características étnico-raciales ${ }^{2}$ como parte del conjunto de circunstancias sociales

${ }^{2}$ Utilizamos el término étnico-racial para destacar que las fronteras que establecen las personas entre lo étnico y lo racial (entendido como construcción social a partir del proceso de racialización) son difusas y difícilmente separables entre sí (Brubaker, 2009; Loveman, 1999, p. 894; Nutini, 1997, p. 228), por lo que, en la práctica, el racismo y la discriminación se fun- 
de origen que afectan las oportunidades de vida. Además, esta desatención no es de sorprender, pues responde a la normalización de las jerarquías étnico-raciales en la sociedad mexicana. Los avances recientes más importantes en esta línea se han dado por los estudios sobre pigmentocracia, que buscan medir los efectos del tono de piel en las oportunidades de vida (Dixon y Telles, 2017). La inclusión de esta variable amplía de forma considerable el campo de estudio de los efectos étnico-raciales, que se había basado fundamentalmente en el criterio lingüístico de adscripción a pueblos indígenas (Ramírez, 2005) y, más recientemente, en la autoadscripción cultural indígena y afromexicana (Barbary, 2015). Los trabajos recientes sobre los efectos del tono de piel han destacado su asociación con los ingresos económicos y la movilidad económica en entornos urbanos (Campos-Vazquez y Medina-Cortina, 2019) así como en las oportunidades educativas y ocupacionales (Telles, Flores y Urrea-Giraldo, 2015; Villarreal, 2010). Otras investigaciones validan los efectos del tono de piel, aunque agregan que éstos se reducen significativamente una vez que se controla estadísticamente por el origen de clase (Flores y Telles, 2012) o el nivel socioeconómico de la familia de origen (Monroy-Gómez-Franco, Vélez-Grajales y Yalonetzky, 2018). Lo anterior sugiere que las diferencias socioeconómicas por color de piel se explican en parte por el efecto de las desventajas históricamente acumuladas debido a la discriminación racial de generaciones anteriores (Flores y Telles, 2012, p. 492).

Si bien estas investigaciones han hecho contribuciones significativas que recuperamos en nuestro análisis, consideramos que el análisis macrosocial de la desigualdad de oportunidades asociada a las características étnico-raciales puede ser mejorado al menos en cinco aspectos.

En primer lugar, es importante considerar el carácter multidimensional de las características étnico-raciales. Los estudios más recientes suelen enfocarse casi exclusivamente en el tono de piel como característica física racializada. Como ya señalamos, unos estudios enfatizan la adscripción lingüística, mientras que otros se orientan a la autoadscripción como criterio de identificación de las personas pertenecientes a pueblos indígenas o afromexicanos. Creemos que, más que enfocarse en un criterio único, cada una de estas características debe ser considerada como indicador de diferentes dimensiones de la caracterización étnico-racial (Roth, 2016). Hablar una lengua indígena es indicativo de la socialización y, por tanto, de la pertenencia arraigada a una colectividad integrada por una lengua común; au-

dan frecuentemente en una mezcla de atributos en ambas dimensiones (Solís, Krozer, Arroyo Batista y Güémez Graniel, 2019). 
toadscribirse como una persona indígena, negra, mestiza o blanca nos habla de la adopción explícita de una identidad étnico-racial; en cambio, el tono de piel, al constituirse socialmente como una característica física racializada, es un proxy de la forma en que las personas son identificadas por terceros como pertenecientes a determinados grupos étnico-raciales. Cada una de estas dimensiones de adscripción étnico-racial puede tener efectos independientes en la probabilidad de acceso a oportunidades de vida. Por tanto, es importante considerarlas en conjunto y no asumir a priori que una es más relevante que la otra.

En segundo lugar, la mayor parte de los estudios sobre la asociación entre las características étnico-raciales y la desigualdad han puesto poca atención en establecer los controles apropiados para controlar los efectos de otras circunstancias sociales de origen y, en particular, de las circunstancias socioeconómicas, tanto de la familia como de la comunidad de origen. El origen socioeconómico se ha operacionalizado a través de una sola dimensión, como una medida gruesa del estatus ocupacional de los padres (Flores y Telles, 2012) o el nivel de riqueza de la familia de origen (Monroy-Gómez-Franco, Vélez-Grajales y Yalonetzky, 2018), o bien, con criterios que mezclan características socioeconómicas, educativas, étnicas y demográficas (Campos-Vazquez y Medina-Cortina, 2019). Para reflejar de mejor manera el carácter multidimensional de las circunstancias sociales de origen (ya discutido en la sección previa), es necesario utilizar medidas que incorporen los tres ejes centrales de la estratificación socioeconómica (educación, ocupación y recursos económicos). Asimismo, se deben considerar no sólo las condiciones socioeconómicas del entorno familiar, sino también las de la comunidad de origen, en tanto las características étnico-raciales se asocian fuertemente a las condiciones de desarrollo socioeconómico locales y regionales.

En tercer lugar, y relacionado con lo anterior, es importante avanzar en la discusión sobre los efectos conjuntos de las condiciones socioeconómicas de origen y las características étnico-raciales en la desigualdad de oportunidades, distinguiendo entre la acumulación histórica de desventajas y la persistencia del racismo y la discriminación étnico-racial en el presente. Como lo sugieren Flores y Telles (2012, p. 492), el hecho de que los efectos del tono de piel sobre los destinos sociales se reduzcan sustancialmente una vez que se controla por el origen de clase, "podría reflejar desventajas acumuladas de la discriminación por color en generaciones previas", que se manifiestan en el presente en una asociación estadística entre el tono de piel y la clase social de los padres. Es decir, dado el carácter histórico del racismo y la discriminación étnico-racial en México, las personas pertenecientes a grupos sociales víctimas de estas prácticas son más proclives a provenir 
de familias situadas en una condición social, económica y geográfica de desventaja.

En términos prácticos, esto implica que, en el análisis estadístico, las características étnico-raciales y socioeconómicas de origen no pueden ser consideradas como variables exógenas e independientes, sino más bien como variables con un determinado grado de correlación entre sí, explicado en parte por la acumulación histórica de desventajas asociada al racismo y la discriminación en generaciones pasadas. Del mismo modo, el hecho de que se reduzca la magnitud de la asociación entre las características étnico-raciales y los destinos sociales, una vez "controladas" las características socioeconómicas de origen, no implica necesariamente una asociación espuria, sino que una parte sustantiva de esta asociación se expresa a través de la acumulación histórica de desventajas. En palabras más simples, pertenecer a un grupo étnico-racial no implica sólo tener (des)ventajas por el racismo y la discriminación del presente, sino también heredarlas debido a la acumulación histórica de (des)ventajas en las generaciones previas.

En cuarto lugar, los estudios previos no han analizado con detalle el papel interviniente de la escolaridad en la asociación entre las características étnico-raciales y los destinos sociales de las personas. Desde mediados de los años sesenta con el trabajo de Blau y Duncan (1967), y en múltiples investigaciones a lo largo del tiempo y en distintas sociedades (Bukodi y Goldthorpe, 2016; Goldthorpe y Jackson, 2008; Shavit y Park, 2016), incluido México (Solís, 2007; Solís y Dalle, 2019), se ha documentado el importante papel de la escolaridad como variable interviniente en la asociación entre orígenes y destinos socioeconómicos. Con estos antecedentes, conviene preguntarse si la escolaridad tiene un papel similar como mediador en la asociación entre las características étnico-raciales y las oportunidades de vida; es decir, en qué medida las disparidades étnico-raciales en destinos socioeconómicos se explican por la desigualdad de oportunidades educativas.

Por último, aunque existe evidencia aislada en México que apunta a diferencias de género en los efectos de las características étnico-raciales (Arceo-Gomez y Campos-Vazquez, 2014), conviene realizar una revisión más sistemática. Cabe recordar que desde su origen en Estados Unidos (Collins, 2015; Crenshaw, 1989), el enfoque de interseccionalidad ha planteado justamente que el efecto combinado de ser mujer y ser negra sobre la desigualdad es mucho mayor que la suma de estas dos condiciones por separado, debido a la potenciación de los efectos de discriminación y racismo. Para el caso de México, esto implicaría que las desigualdades asociadas a las características étnico-raciales fuesen mayores para las mujeres que para los varones. 
A partir de la discusión precedente, podemos formular con mayor detalle los alcances y preguntas principales de nuestro trabajo. Nos interesa analizar con un enfoque macrosocial los efectos de las características étnico-raciales sobre los destinos económicos de las personas mediante una aproximación multidimensional, con énfasis en cuatro grupos de preguntas:

1) ¿Cuál es la asociación entre cada una de las dimensiones étnico-raciales consideradas en este trabajo (autoadscripción, lengua indígena y tono de piel) y los destinos económicos de las personas? ¿Es posible identificar un efecto mayor asociado a alguna de estas tres dimensiones?

2) ¿En qué medida los efectos de las características étnico-raciales son explicados por la acumulación histórica de desventajas, es decir, por su asociación con las características socioeconómicas de origen? ¿Existen efectos persistentes en el presente, incluso controlando por el origen socioeconómico?

3) ¿Cuál es el papel mediador de la escolaridad en la asociación entre las características étnico-raciales y los destinos económicos?

4) ¿Es posible identificar diferencias de género en estos efectos?

\section{Metodología}

\section{Datos}

Utilizamos el Módulo de Movilidad Social Intergeneracional (MMSI) levantado por el Instituto Nacional de Estadística y Geografía de México (INEGI) en el 2016 como parte de la Encuesta Nacional de los Hogares. ${ }^{3} \mathrm{La}$ población estudiada son personas de 25 a 64 años, residentes de viviendas particulares en México. La muestra es probabilística, con 25634 casos, y es representativa a nivel nacional.

Además de incluir datos socioeconómicos de la persona en el momento de la entrevista, el módulo cuenta con información referente a la situación educativa, ocupacional y económica de los padres o el principal proveedor económico del hogar (PPEH) cuando la persona entrevistada tenía 14 años. También incluye preguntas sobre las características étnico-raciales de las personas en tres dimensiones: la lingüística, la de autoadscripción, y el tono de piel autorreportado.

\footnotetext{
${ }^{3}$ Los datos se encuentran disponibles en https://www.inegi.org.mx/programas/mmsi/2016/
} 


\section{Variables}

Nuestro interés es analizar los efectos de las características étnico-raciales sobre los destinos económicos de las personas. Para medir el destino económico, construimos un índice de activos económicos (IAE) a partir de la información proporcionada por las personas entrevistadas sobre la posesión de bienes, servicios y activos personales y en la vivienda. ${ }^{4}$ En ausencia de información directa, este tipo de índices son una buena aproximación al ingreso permanente y nivel de riqueza de los hogares (Alkire y Santos, 2010; Filmer y Pritchett, 2011).

En este caso, el índice fue construido mediante la técnica de análisis factorial policórico por componentes principales, utilizando el primer componente, que absorbe el $47 \%$ de la varianza conjunta. Posteriormente, el índice fue transformado a una escala percentílica, de modo que su valor reflejase el percentil económico en el que se ubica la persona en la distribución total.

Construimos una variable nominal por cada una de las tres características étnico-raciales incluidas en el cuestionario. En el caso de la identificación lingüística, adoptamos tres categorías según el manejo de lengua indígena del entrevistado o sus padres: 1) las personas sin padres hablantes de lenguas indígenas (no hablantes); 2) las personas no hablantes de lenguas indígenas, pero con padres hablantes (padres hablantes); y 3) las personas hablantes de lenguas indígenas (hablantes).

Para la autoadscripción étnico-racial retomamos la pregunta 10.3 del cuestionario, que dice: "En nuestro país viven personas de múltiples orígenes raciales, ¿se considera usted una persona...?”, con las siguientes opciones de respuesta: negra o mulata; indígena; mestiza; blanca; y otra raza (asiática, eurodescendiente). La variable que construimos utiliza las mismas opciones como categorías, con la excepción de que agrupamos las opciones de blanca y mestiza. Esta decisión obedece a que, a diferencia de otros países, como Argentina, Costa Rica o Uruguay, donde la identidad blanca tuvo un papel protagónico en la identidad nacional, en México las fronteras simbólicas entre lo blanco y lo mestizo no se encuentran claramente definidas (Casas Martínez, Saldívar, Flores y Sue, 2014, p. 59).

${ }^{4}$ Los bienes, servicios y activos considerados fueron: refrigerador, plancha eléctrica, licuadora, estufa de gas o eléctrica, lavadora de ropa, televisión de paga, teléfono fijo, DVD/ blu-ray, horno de microondas, ventilador, consola de videojuegos, tostador eléctrico de pan, acceso a internet, contar con más de nueve focos, impresora, automóvil o camioneta, propiedades o bienes raíces, y el número de residentes en la vivienda dividido entre el número de cuartos para dormir en la vivienda (índice de hacinamiento). 
Finalmente, para la dimensión de tono de piel usamos la pregunta 10.2, donde se les pide a los entrevistados identificar el color de piel de su cara a partir de la escala PERLA (Proyecto sobre Etnicidad y Raza en Latinoamérica) (véase el Anexo). Esta escala cromática cuenta con once opciones de respuesta que van de la letra A a la $\mathrm{K}$. Con base en éstas, y tratando de buscar proporcionalidad entre los subgrupos, reorganizamos la variable en cuatro categorías: oscuro (A-F), moreno $(\mathrm{G})$, moreno claro $(\mathrm{H})$ y claro (I-K).

En la discusión inicial enfatizamos la importancia de utilizar mejores indicadores de las circunstancias socioeconómicas de origen de las personas. Para ello, construimos un índice de orígenes sociales (IOS) que sintetiza la posición educativa, ocupacional y económica de origen de la persona entrevistada. Como indicador de la dimensión educativa, usamos los años de escolaridad de la persona que era la principal proveedora económica del hogar (PPEH) cuando el entrevistado tenía 14 años. Por su parte, la dimensión ocupacional contempla la posición del PPEH a los 14 años en el International Socioeconomic Index of Occupational Status (ISEI), diseñado por Ganzeboom y Treiman (1996), que asigna un puntaje según los promedios ponderados de medidas estandarizadas de ingreso y educación para cada categoría ocupacional. Finalmente, para la dimensión económica construimos un índice de activos y servicios que toma como insumos la disponibilidad de bienes, activos y características de la vivienda de la persona cuando tenía 14 años. El índice se construyó mediante la técnica estadística de análisis factorial por componentes principales. La versión específica que se utilizó fue la del análisis factorial policórico (Kolenikov y Angeles, 2004).

Construimos el IOS mediante la técnica de análisis factorial tomando como insumo las variables estandarizadas correspondientes a cada una de las dimensiones recién descritas (el ISEI, el índice de activos y servicios de la familia de origen, y los años de escolaridad). Como resultado de la progresiva ampliación del acceso a bienes, a la vivienda, así como a la educación formal, para los padres de los entrevistados con más edad el acceso a dichos servicios era comparativamente menor al de los padres de los entrevistados más jóvenes, por lo que el IOS presentaba una correlación con la cohorte de nacimiento. Para corregir esto, estandarizamos el IOS para cada cohorte construida a partir de grupos de edades quinquenales. De este modo, el IOS refleja la posición relativa de la familia de origen en la cohorte de nacimiento de la persona entrevistada.

Adicionalmente al IOS, incluimos en nuestro análisis las condiciones socioeconómicas de la municipalidad de origen mediante el índice de marginación municipal (IMM) del municipio de residencia a los 14 años de edad (Conapo, 1994). Este índice resume el nivel de desarrollo socioeco- 
nómico del municipio a partir de un conjunto de indicadores agregados de escolaridad, ingresos de los hogares y condiciones físicas de las viviendas. Utilizamos el valor del índice para el año 1990.

Por último, medimos la escolaridad a través del número de años aprobados por la persona entrevistada.

\section{Modelos}

Debido a que el índice de activos económicos (IAE) es una variable continua, optamos por utilizar modelos de regresión lineal múltiple. ${ }^{5}$ Ajustamos un total de seis modelos, por separado para hombres y mujeres. Los modelos 1 a 3 incluyen individualmente a cada una de las características étnico-raciales, además de controles básicos por edad y situación conyugal. Esto permite realizar una primera evaluación de la relación bivariada entre cada característica en lo individual y los destinos económicos. El modelo 4 incluye simultáneamente las tres variables étnico-raciales, lo cual permite evaluar su efecto individual una vez que se controlan las otras dimensiones étnico-raciales. El modelo 5 introduce las dos variables de orígenes socioeconómicos, lo que permite identificar la magnitud del efecto de las características étnico-raciales que es atribuible a su asociación con las condiciones socioeconómicas familiares y geográficas de origen. Finalmente, el modelo 6 incluye, además de las variables anteriores, los años de escolaridad. El contraste de los coeficientes de los modelos 5 y 6 indica en qué medida la asociación entre las características étnico-raciales y los destinos económicos se explica por la desigualdad de las oportunidades educativas.

\section{Resultados}

\section{Características étnico-raciales, orígenes socioeconómicos y destinos económicos}

En el Cuadro 1 presentamos la distribución de la muestra según cada una de las características étnico-raciales. Un poco más de 7\% de la población es hablante de alguna lengua indígena, $8.3 \%$ no es hablante, pero tiene alguno

\footnotetext{
${ }^{5}$ Para evaluar posibles sesgos asociados al hecho de que el IAE no se distribuye como una variable normal, ajustamos modelos alternativos de regresión cuantílica para la mediana. Los resultados (no mostrados en este trabajo) son similares a los aquí reportados.
} 
de sus padres hablantes, y el $84 \%$ restante no habla alguna lengua indígena ni tiene padres hablantes.

\section{Cuadro 1}

Características étnicas y raciales, por sexo

\begin{tabular}{lrrr}
\hline & Hombres & Mujeres & Total \\
\hline Identificación lingüistica & & & \\
Hablantes lenguas indígenas & 7.5 & 7.3 & 7.4 \\
Padres hablantes lenguas indígenas & 8.4 & 8.3 & 8.3 \\
No hablantes lenguas indígenas & 84.1 & 84.4 & 84.3 \\
Total & 100.0 & 100.0 & 100.0 \\
\hline Autoadscripción étnico-racial & & & \\
Indígena & 13.8 & 14.0 & 13.9 \\
Mestiza o blanca & 74.7 & 71.2 & 72.8 \\
Negra o mulata & 2.6 & 2.6 & 2.6 \\
Otra & 0.5 & 0.5 & 0.5 \\
Sin autoadscripción & 8.4 & 11.7 & 10.2 \\
Total & 100.0 & 100.0 & 100.0 \\
\hline Tono de piel & & & \\
Oscuro & 26.5 & 15.1 & 20.5 \\
Moreno & 31.0 & 29.1 & 30.0 \\
Moreno claro & 31.9 & 42.3 & 37.4 \\
Claro & 10.7 & 13.5 & 12.1 \\
Total & 100.0 & 100.0 & 100.0 \\
\hline
\end{tabular}

Fuente: Estimaciones propias a partir de los datos del Módulo de Movilidad Social Intergeneracional (MMSI) 2016, INEGI.

Con respecto a la autoadscripción étnico-racial, la mayor parte de las personas se identifican como blancas o mestizas, con $72.8 \%$ del total. ${ }^{6}$ Le siguen quienes se autoadscriben como indígenas, con $13.9 \%$. Un $2.6 \%$ se asume como personas negras o mulatas, y $0.5 \%$ en otros grupos. Un dato que llama la atención es que, una vez que se les mencionaron directamente todas las opciones, $10.2 \%$ de las personas no eligieron ninguna adscripción. Esto revela que la mayoría de las personas (casi 90\%) se autoadscriben en algún grupo étnico-racial, a pesar de que, con excepción de la categoría indígena,

${ }^{6}$ Entre estas dos, la categoría de autoadscripción predominante es por mucho la de mestizo/a, con $61.5 \%$ del total de personas entrevistadas. 
las otras categorías no forman parte de ninguna clasificación oficial, no son usadas en trámites oficiales o de otro tipo, ni son preguntadas frecuentemente en instrumentos como censos o encuestas nacionales.

Por último, cerca de la mitad de las personas se clasifican en los tonos moreno oscuro (20.5\%) y moreno $(30.0 \%)$ de la escala PERLA, $37.4 \%$ en moreno claro y sólo $12.1 \%$ en el tono claro. A diferencia de las otras dos dimensiones, en las que no hay grandes diferencias por sexo, se aprecia que las mujeres tienden a clasificarse en tonos más claros que los hombres. Así, sólo $15.1 \%$ de las mujeres se ubicaron en el tono oscuro, frente a $26.5 \%$ de los hombres; en cambio, $42.3 \%$ de ellas se definieron como de piel morena clara, frente a $31.9 \%$ de los varones. Aunque es necesario investigar más a fondo su explicación, este resultado -que ha sido reportado también en estudios previos (Telles, 2004)- podría reflejar un caso peculiar de interseccionalidad en el que confluyen los estereotipos raciales y de género (Viáfara López y Urrea Giraldo, 2006; Wade, Urrea-Giraldo y Viveros Vigoya, 2008): debido a los prejuicios racistas, la piel clara es considerada más atractiva que la piel oscura (Aguilar, 2011; Navarrete Linares, 2016); por su parte, las mujeres enfrentan mayores presiones sociales que los hombres para ajustarse a los estándares de belleza, lo cual las llevaría a "blanquear" su tono de piel más que los varones.

En la discusión inicial enfatizamos la importancia de considerar la asociación entre las dimensiones étnico-raciales y los orígenes socioeconómicos familiares como una forma de hacer evidentes los efectos históricos del racismo y la discriminación étnico-racial acumulados en generaciones pasadas. La magnitud de estos efectos se aprecia al observar las desigualdades en la distribución del índice de orígenes sociales (IOS) para las categorías de cada una de las variables étnico-raciales (Gráfica 1).

Las personas hablantes de lenguas indígenas, autoadscritas como indígenas y con tonos oscuros de piel provienen de familias con mayores desventajas educativas, ocupacionales y económicas. En particular, sobresale la dimensión lingüística como la de mayor desigualdad en los orígenes socioeconómicos familiares. La distribución de personas hablantes de lenguas indígenas en el cuartil socioeconómico menos privilegiado es desproporcionadamente mayor que la del resto de las categorías en esa y las demás dimensiones. Asimismo, las disparidades entre hablantes e hijos de hablantes sugieren que la transmisión intergeneracional de la lengua indígena está vinculada a las condiciones socioeconómicas de los padres: en la medida en que éstas son más aventajadas, menor es la probabilidad de que sus hijos sean hablantes, y viceversa. 


\section{Gráfica 1}

Distribución de la densidad del índice de orígenes sociales por características étnico-raciales

a) Identificación lingüística

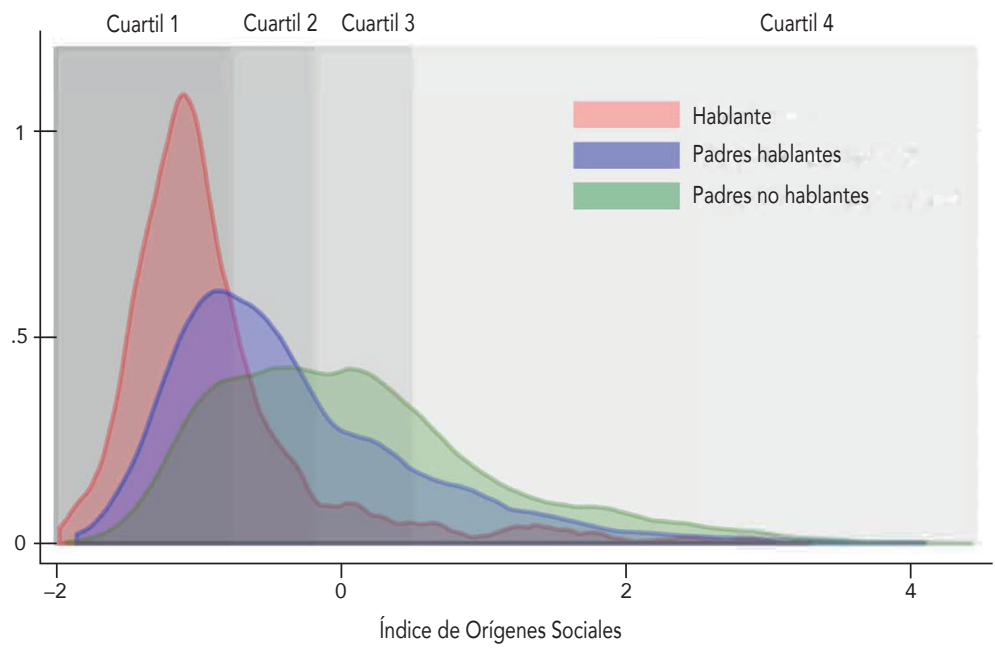

b) Autoadscripción étnico-racial

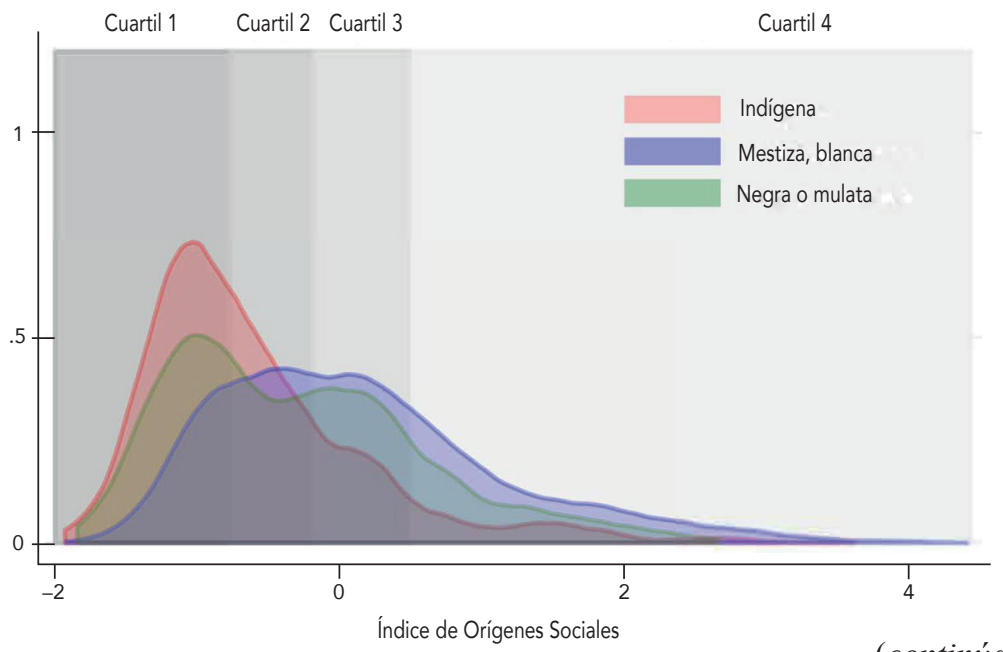

(continúa)

Estudios Demográficos y Urbanos, vol. 36, núm. 1 (106), enero-abril, 2021, pp. 255-289 http://dx.doi.org/10.24201/edu.v36i1.2078 
c) Tonos de piel

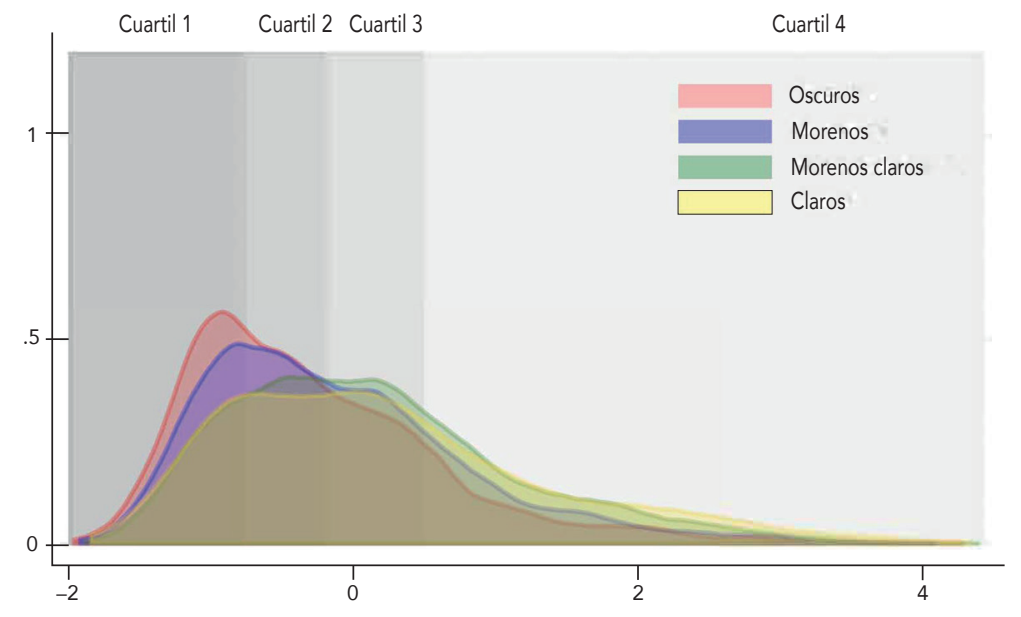

Fuente: Elaboración propia a partir de los datos del MMSI 2016, INEGI.

En la distribución del IOS según autoadscripción étnico-racial también se observan diferencias notables entre las personas indígenas y las demás, aunque éstas son de menor magnitud que en el caso de la identificación lingüística. Finalmente, la dimensión donde se exhiben menos contrastes entre categorías es la del tono de piel.

Estos resultados revelan que los efectos de la desigualdad étnico-racial son experimentados por las personas desde muy temprano en sus vidas a través de la acumulación de desventajas previas a su nacimiento, que las lleva a tener mayor probabilidad de nacer y crecer en familias con desventajas socioeconómicas. En los apartados siguientes, cuando revisemos los resultados de los modelos de regresión, volveremos a este tema y sus consecuencias para la interpretación de los efectos de las características étnico-raciales en la desigualdad de oportunidades económicas.

Otro aspecto que es importante analizar es el grado de asociación entre cada una de las tres dimensiones étnico-raciales. ¿Existe una asociación en la forma en que las personas se autoadscriben en cada uno de estos criterios? ¿En qué medida, por ejemplo, las personas que declaran su adscripción étnico-racial como indígena son las mismas que hablan lenguas indígenas o tienen padres que lo hacen? En el Cuadro 2 se presentan tablas de doble entrada con la clasificación conjunta para cada par de criterios. 


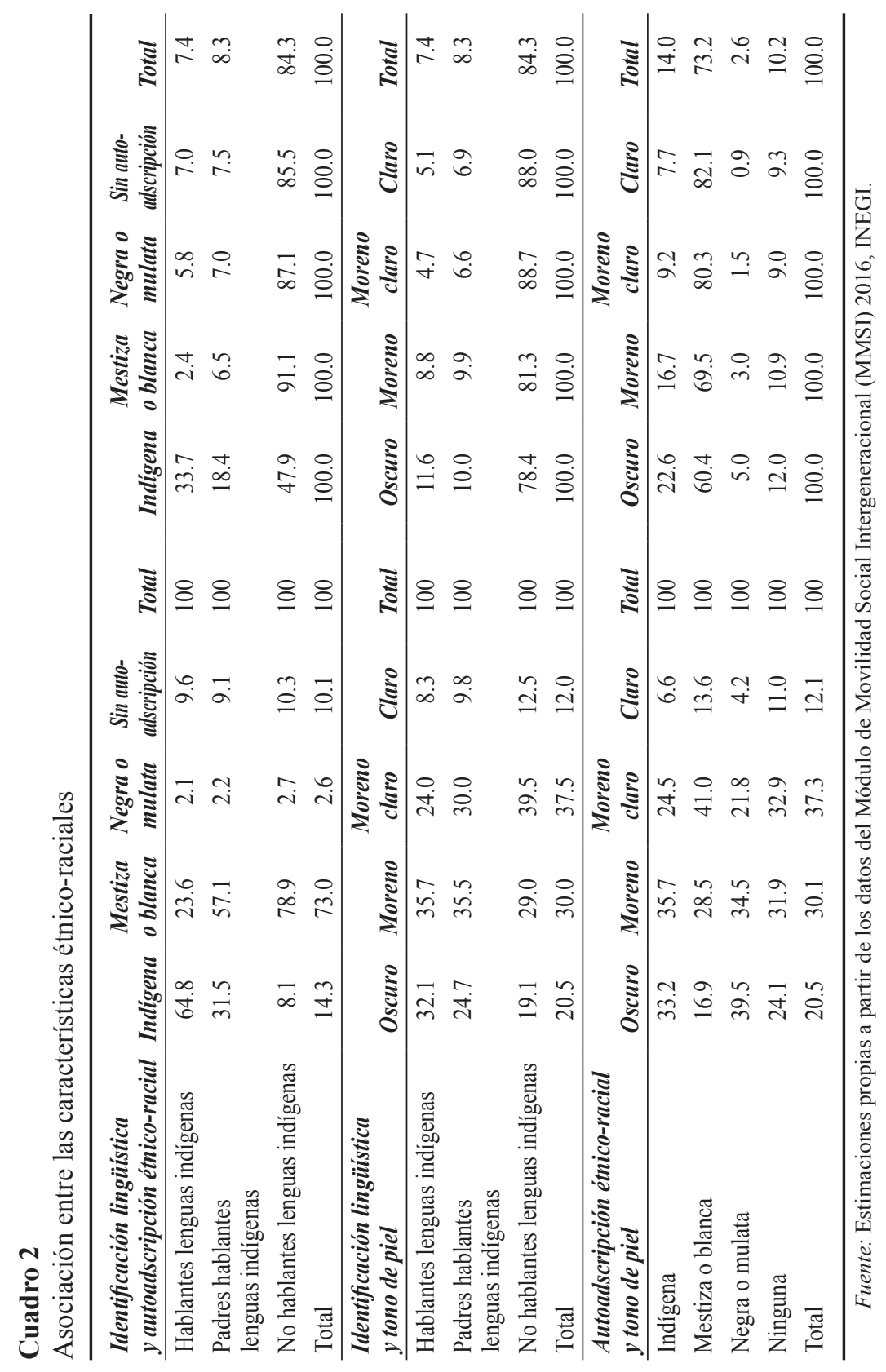


Con respecto a la identificación lingüística y la autoadscripción étnico-racial, se observa que casi dos terceras partes (64.8\%) de las personas hablantes también se autoadscriben como indígenas, lo cual implica, en contraste, que más de una tercera parte no se reconoce en este grupo de autoadscripción. Entre las personas con padres hablantes, la proporción que se autoadscribe como indígena es mucho menor (31.5\%), mientras que una mayoría $(57.1 \%$ ) se clasifica como mestiza o blanca. Por su parte, $78.9 \%$ de quienes no hablan lenguas indígenas se autoadscriben como mestizos o blancos. Cuando se revisa esta distribución desde la perspectiva de la autoadscripción del panel derecho, destaca que casi la mitad (47.9\%) de quienes se autoadscriben como indígenas no hablan lenguas indígenas ni tienen padres que lo hacen, lo cual sugiere que el alcance de la autoadscripción es mucho mayor que el de la identificación lingüística. Por su parte, $14.5 \%$ de las personas que se autoadscriben como negras o mulatas hablan lenguas indígenas o tienen padres que lo hacen, situación que refleja la existencia de grupos poblacionales con orígenes étnicos mixtos entre poblaciones afrodescendientes e indígenas.

La asociación entre la identificación lingüística y el tono de piel es menos fuerte, aunque sí se observa que, con respecto a las personas no hablantes, las que son hablantes de lengua indígena declaran con mayor frecuencia tono de piel oscuro (32.1\% versus $19.1 \%$ ) y con menor frecuencia tono de piel moreno claro $(24.0 \%$ frente a $39.5 \%)$. Estas diferencias, sin embargo, son apenas perceptibles cuando las analizamos desde la perspectiva de la distribución de cada categoría de tono de piel: en todos los casos predominan las personas no hablantes de lenguas indígenas, con porcentajes que van del $78.4 \%$ (tono oscuro) al $88.0 \%$ (tono claro).

La autoadscripción étnico-racial también presenta una asociación moderada con el tono de piel. Las personas que se autoadscriben como negras o mulatas sistemáticamente se ubican en los tonos de piel más oscuros: $39.5 \%$ en la categoría de tono oscuro y $34.5 \%$ en la de moreno; le siguen de cerca las personas que se autoadscriben como indígenas (33.2 y $35.7 \%$ ); en contraste, las personas mestizas o blancas tienen menores porcentajes en estas categorías (16.9 y $28.5 \%$, respectivamente), y mucha mayor concentración en la categoría de moreno claro $(41.0 \%)$ y claro (13.6\%).

Estas comparaciones revelan un aspecto importante de nuestra aproximación a la caracterización de los rasgos étnicos y raciales de las personas: aunque existe en todos los casos cierta asociación entre la identificación lingüística, la autoadscripción étnico-racial y el tono de piel, esta asociación es moderada, e incluso podría clasificarse como débil. 


\section{Gráfica 2}

Distribución del índice de riqueza según la combinación de autoadscripción étnico-racial, adscrición lingüística a lenguas indígenas y tono de piel. Personas entre 25 y 64 años, 2016

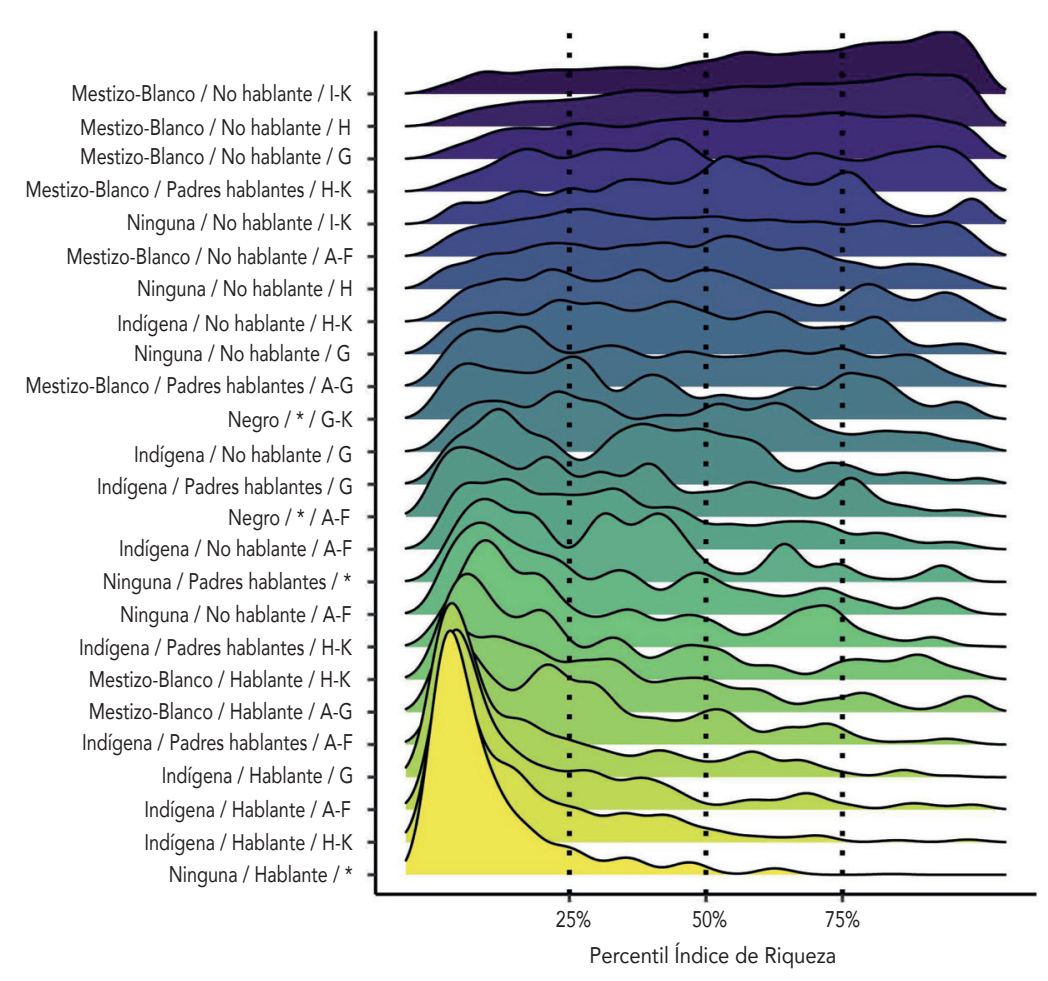

\footnotetext{
${ }^{a}$ Los tonos de piel se clasifican de $\mathrm{A}$ a $\mathrm{K}$, donde $\mathrm{K}$ es el tono más claro.

* Agrupa a todos los valores.

Fuente: Estimaciones propias a partir del MMSI 2016, INEGI.
}

Por último, el análisis descriptivo preliminar de la asociación entre la combinación de las características étnico-raciales y el IAE (Gráfica 2) permite identificar su correlación con los destinos económicos. Destaca, en primer lugar, que la distribución del índice de activos tiene un marcado sesgo hacia los niveles bajos entre las personas hablantes de lenguas indígenas, independientemente de su autoadscripción étnica y tono de piel. Incluso quienes tienen padres hablantes, pero no conservaron el uso de la lengua indígena, tienen 
mejores posiciones económicas que los hablantes, lo que apunta a las desventajas sociales que sufren quienes preservan su lengua materna.?

En contraste, las personas que se autoadscriben como mestizas o blancas, que no son hablantes ni tienen padres hablantes de lenguas indígenas, son quienes presentan las distribuciones con valores más positivos, tendencia que se acentúa entre quienes tienen los tonos de piel más claros (I-K). En general, se percibe que las tres dimensiones marcan diferencias importantes en los destinos económicos, en gradientes que apuntan hacia una mayor desventaja para quienes poseen rasgos étnico-raciales más afines con la identificación con pueblos indígenas o afrodescendientes.

Este análisis descriptivo ofrece evidencia preliminar de que una perspectiva multidimensional para la caracterización étnico-racial puede ser útil como herramienta para el análisis de sus efectos en la desigualdad de oportunidades económicas. No obstante, para obtener estimaciones más robustas es necesario recurrir a técnicas de regresión, pues éstas permiten establecer no sólo controles simultáneos para cada una de estas dimensiones, sino también para otras características socioeconómicas.

\section{Modelos de regresión}

En el Cuadro 3 presentamos los resultados de las regresiones lineales para hombres y mujeres. Como señalamos antes, para los primeros tres modelos estimamos el efecto de las tres dimensiones étnico-raciales por separado. Se puede ver que los efectos de mayor magnitud se encuentran en el modelo que incluye la dimensión lingüística (modelo 2) y particularmente en la diferencia entre hablantes y no hablantes de lenguas indígenas. Así, manteniendo constantes la edad y la situación conyugal, las mujeres no hablantes de lenguas indígenas se ubican en promedio 34.8 puntos percentiles por encima del percentil promedio de las mujeres hablantes de lenguas indígenas. En cuanto a la autoadscripción étnico-racial, se observa que, manteniendo el resto de las variables constantes, la categoría blanca o mestiza, tanto para hombres como para mujeres, se encuentra 23.9 percentiles por encima del promedio de las personas autoadscritas como indígenas. Por su parte, en la

${ }^{7}$ La desigualdad económica entre quienes heredan la lengua y quienes no lo hacen está también asociada a las brechas de oportunidades en el ámbito rural versus el urbano. La migración a la ciudad por parte de familias de personas hablantes de lenguas indígenas se puede traducir tanto en una mejora de oportunidades económicas como en la pérdida intergeneracional de la lengua materna. En el análisis posterior buscamos controlar este efecto mediante la inclusión del índice de marginación municipal en la regresión lineal. 
dimensión del tono de piel encontramos diferencias de menor tamaño, aunque también sustantivas: el percentil promedio del IAE para quienes tienen tonos claros es mayor en 15.0 y 18.6 puntos para hombres y mujeres, respectivamente, con respecto a quienes tienen tono moreno oscuro.

Destaca además que la bondad de ajuste es sustancialmente menor para el modelo bivariado con el tono de piel $\left(R^{2}=.04\right.$ y .06) en comparación con los modelos con autoadscripción y lengua indígena, que en todos los casos superan valores de 0.10 en la $R^{2}$. Esto sugiere que, comparada con las otras dos dimensiones étnico-raciales, el tono de piel es la que tiene menor poder predictivo de los resultados económicos, lo cual remarca la importancia de realizar una aproximación multidimensional a lo étnico-racial en México, que no caiga en el reduccionismo de considerar como aspecto único o principal las características físicas racializadas resumidas en el tono de la piel, sino también considere los rasgos culturales y lingüísticos.

$\mathrm{Al}$ añadir en el modelo 4 las tres dimensiones étnico-raciales de forma simultánea, se reduce el tamaño de los coeficientes para todos los casos, aunque mantienen significancia estadística (con excepción de la categoría de autoadscripción negra o mulata). Por ejemplo, el modelo 4 estima que los hombres mestizos o blancos, manteniendo constantes el efecto de las otras características étnico-raciales, se encuentran 13.6 puntos percentiles por encima de quienes se adscriben como indígenas, una reducción del $43 \%$ de la brecha con respecto al modelo 1 . La diferencia observada entre los coeficientes obedece a la correlación entre las características étnico-raciales, ya discutida en la primera sección de resultados. En este modelo también se confirma lo observado en los tres modelos previos: las características étnico-raciales con mayores efectos en la desigualdad de oportunidades económicas se encuentran en la dimensión lingüística, a la que le sigue la de la autoadscripción étnico-racial y, por último, la del tono de piel.

En el modelo 5 añadimos las variables de orígenes socioeconómicos: el IOS y el IMM. Como era previsible, observamos que, además de tener efectos considerables, contribuyen a mejorar significativamente la capacidad predictiva del modelo: la $R^{2}$ se incrementa a 0.43 y 0.40 para hombres y mujeres, respectivamente. A cada incremento de una desviación estándar del IOS corresponde un aumento promedio de 13.9 puntos percentiles en la posición económica para el caso de los hombres y de 12.5 para el de las mujeres. Por su parte, el incremento de una desviación estándar en el IMM conlleva una reducción de poco más de 4 puntos percentiles en el índice de activos económicos.

A pesar de que la inclusión del IOS y el IMM genera una reducción significativa en los efectos de las características étnico-raciales (que en la 
mayoría de los casos disminuyen en más del 50\%), se mantienen en todos los casos los contrastes estadísticamente significativos entre las características étnico-raciales. Por ejemplo, la brecha entre las mujeres hablantes y las no hablantes de lenguas indígenas era de 26.1 puntos en el modelo 4; al incorporar el IOS y el IMM al modelo, esta brecha se reduce a 11.5 puntos, un coeficiente todavía estadísticamente significativo y con una magnitud importante, aunque $56 \%$ menor. Es decir, aunque una fracción importante de la asociación entre las características étnico-raciales y los destinos económicos se explica por su correlación con las condiciones socioeconómicas de origen, familiares y geográficas, persiste un efecto en los destinos económicos que no puede ser explicado por las disparidades socioeconómicas de origen.

Una vez que se consideran los orígenes sociales queda preguntarse en qué medida la desigualdad de destinos económicos entre las características étnico-raciales está asociada a la diferencia en los años de escolaridad acumulados. En el último modelo indagamos sobre esto añadiendo los años de escolaridad como variable explicativa. Como es esperado, la escolaridad está fuertemente asociada a los destinos económicos de las personas. En este caso, cada año de escolaridad incrementa un promedio de 11.3 puntos percentiles en la posición económica de los hombres y 11.7 percentiles entre las mujeres. Asimismo, cabe destacar que el efecto del IOS se redujo en $45 \%$ tanto para hombres como para mujeres, lo que indica que la escolaridad es un mediador significativo del efecto del índice de orígenes sociales, resultado que es compatible con otros análisis de movilidad social en el país y la región (Solís y Dalle, 2019). Finalmente, aunque se reportan valores inferiores, lo cual sugiere un moderado efecto de mediación de la escolaridad, todos los coeficientes de los efectos de las características étnico-raciales se mantienen estadísticamente significativos.

En síntesis, los modelos de regresión revelan que las características étnico-raciales se asocian significativamente a la desigualdad de oportunidades económicas, así como que esta asociación se debe en parte, pero no en todo, a la acumulación de las desventajas en las generaciones previas y a las desigualdades educativas actuales. Una forma más ilustrativa de visualizar lo anterior es calcular las brechas en el IAE a partir de los distintos modelos de regresión para dos combinaciones extremas de características étnico-raciales (Gráfica 3). En el panel izquierdo de la gráfica hicimos el primer cálculo considerando únicamente la asociación de los perfiles con los destinos económicos (modelo 4). En el panel intermedio calculamos el percentil promedio para ambos perfiles, neto del efecto de los orígenes sociales (modelo 5), y en el último añadimos como control estadístico los años de escolaridad (modelo 6). 


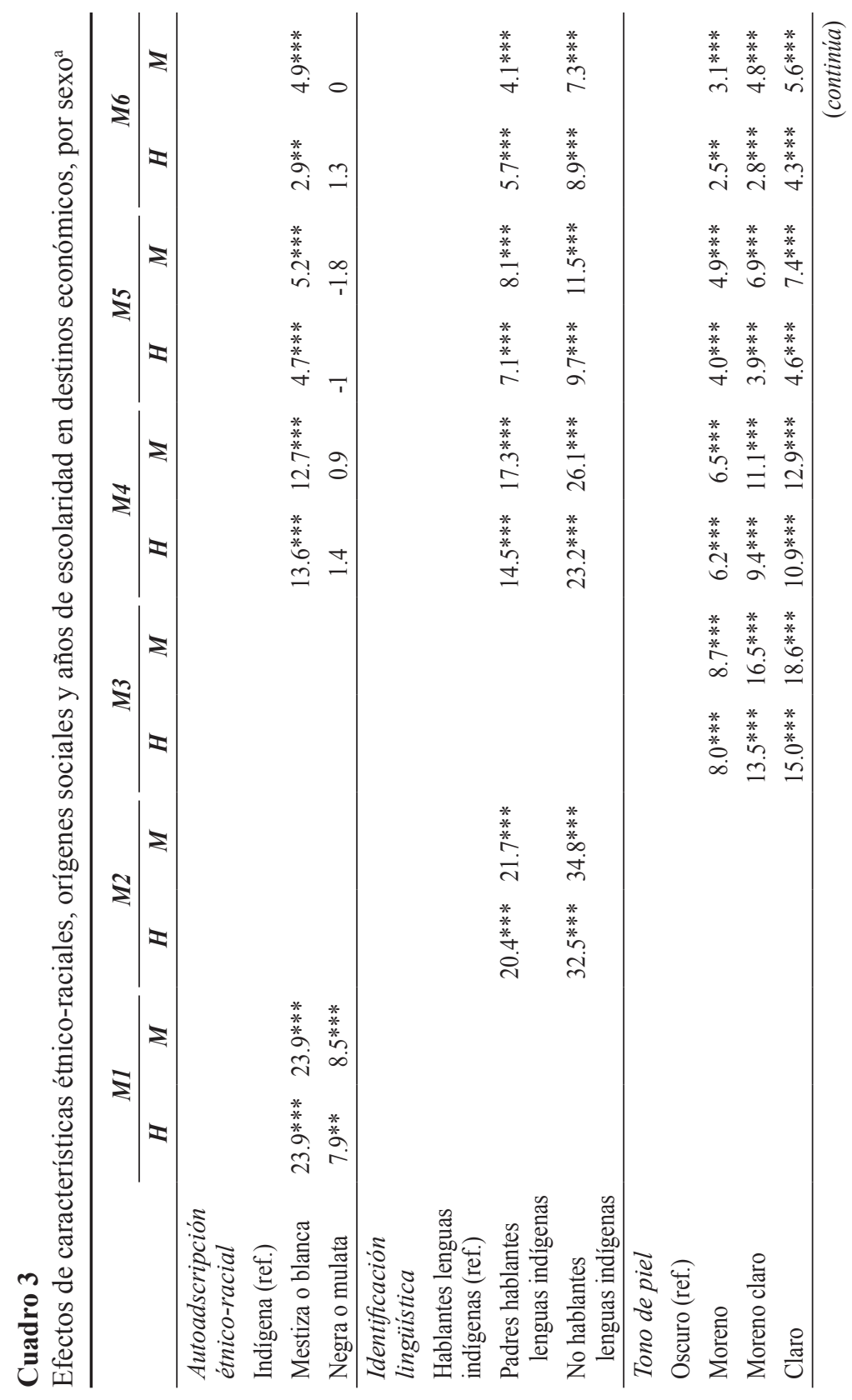




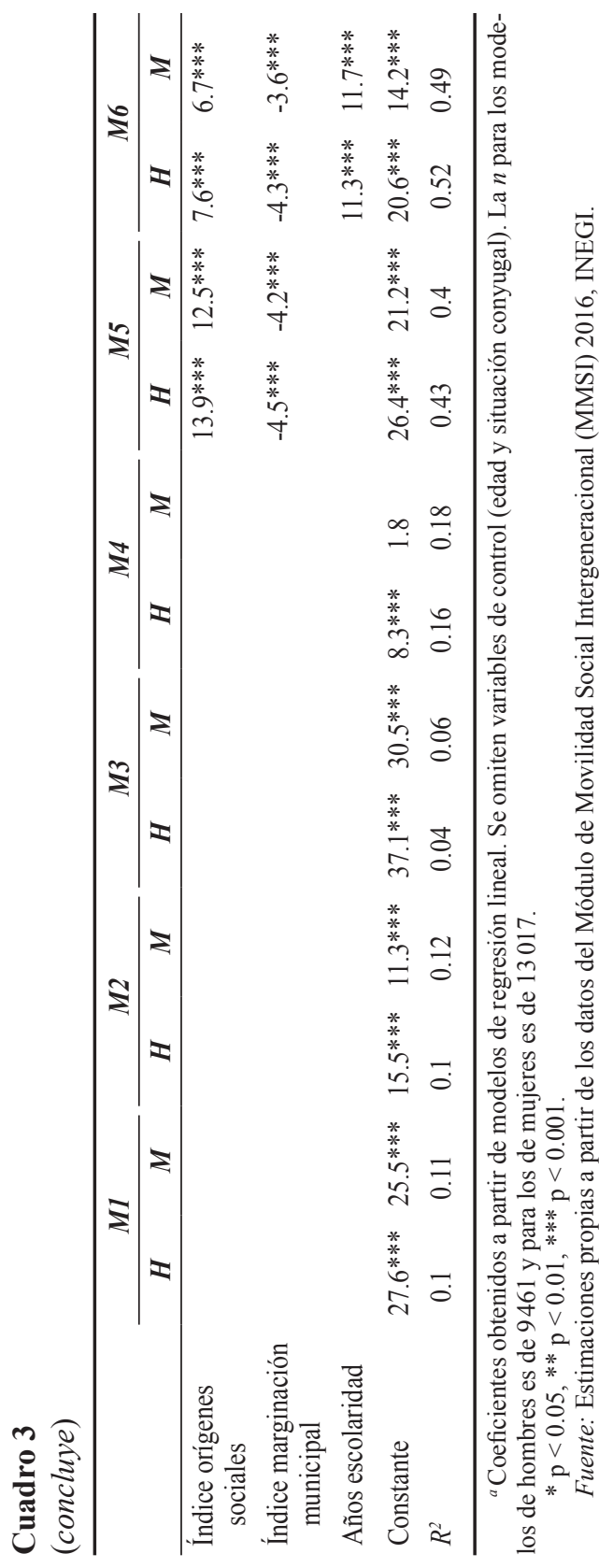




\section{Gráfica 3}

Percentil promedio estimado del índice de riqueza para perfiles étnico-raciales extremos (autoadscripción, lengua indígena y tono de piel), bajo tres modelos de regresión. México, 2016

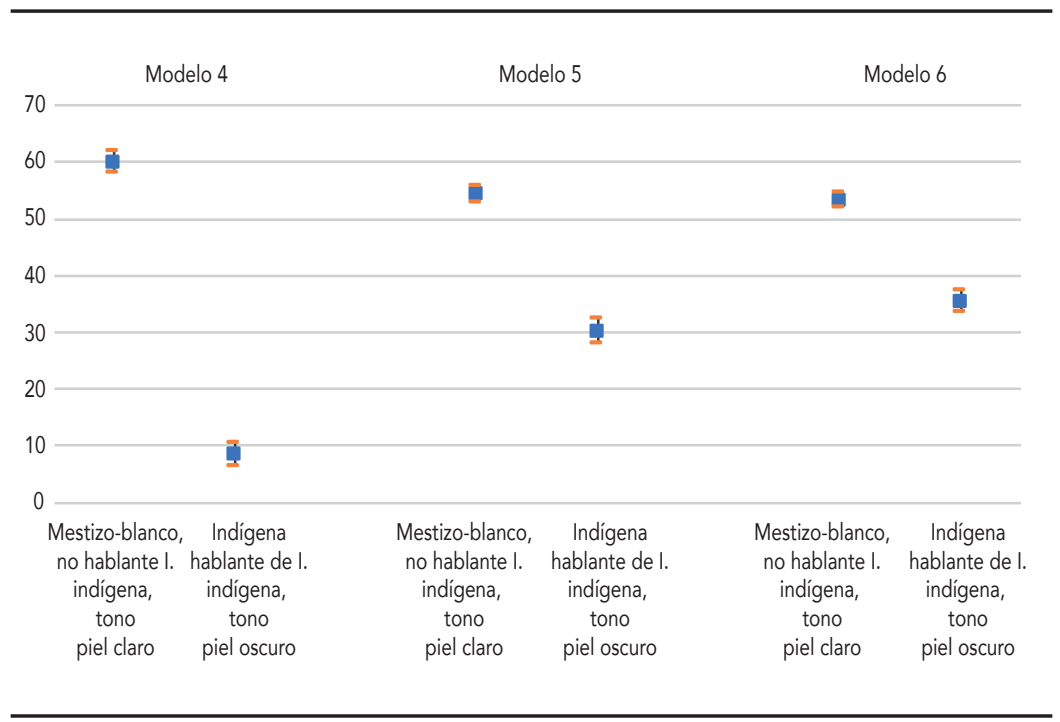

Fuente: Estimaciones propias a partir de los modelos de Cuadro 3.

En el primer modelo, la diferencia estimada del percentil promedio entre mestizos o blancos, no hablantes de lenguas indígenas, con tonos claros de piel, y los autoadscritos como indígenas, hablantes de lenguas indígenas, con tonos oscuros de piel, es de 50 puntos. Como muestra el siguiente modelo, la brecha entre las posiciones económicas estimadas de ambos perfiles disminuye al igualar a niveles promedio los orígenes sociales, aunque sigue siendo significativa: se estima un percentil promedio de 54 para el primer perfil versus uno de 30 para el segundo, es decir, 24 puntos de diferencia. Finalmente, en el último modelo se muestra que, al igualar los años de escolaridad, las brechas disminuyen (18 puntos de diferencia), aunque éstas siguen siendo de una magnitud considerable. A partir de estos resultados, constatamos que la desigualdad étnico-racial en los destinos económicos se asocia de manera significativa por las desventajas acumuladas de generaciones anteriores, pero también a la persistencia del racismo y la discriminación del presente. 


\section{Discusión y conclusiones}

Es conveniente discutir los resultados a partir de las preguntas que nos planteamos al inicio del trabajo. En primer lugar, nos preguntamos cuál es la asociación entre las características étnico-raciales y los destinos económicos, y si es posible identificar diferencias entre cada dimensión en el grado de asociación. Nuestros resultados indican que, para todos los modelos examinados, las tres características tienen una asociación no sólo estadísticamente significativa, sino también de una magnitud sustantiva con el índice de activos económicos. Destaca la dimensión lingüística como una variable cuyos efectos son mayores a los de las otras dos dimensiones. La autoadscripción étnico-racial, y en particular la mestiza o blanca en contraste con la indígena, tiene un efecto menor que el observado para la dimensión lingüística, pero mayor con respecto al tono de piel.

De ese modo, en lugar de ser una ventaja que proporcione acceso a oportunidades, el bilingüismo indígena / castellano en México se asocia a menores oportunidades económicas. Esto se explica en parte por el estigma negativo vinculado al uso de lenguas indígenas, que se desdobla en prácticas específicas de discriminación (Solís, Krozer, Arroyo Batista y Güémez Graniel, 2019). Esta doble asociación puede llevar a que las personas hablantes de lenguas indígenas decidan no transmitir la lengua indígena a su descendencia, sobre todo cuando alcanzan más años de escolaridad, como muestra el trabajo de Villarreal (2014). El mecanismo es consistente con nuestros resultados: al tener orígenes sociales más altos (en relación con los hablantes) y estar expuestos a un menor estigma social, los hijos de hablantes indígenas que dejan de usar la lengua alcanzan una posición económica de mayor ventaja que sus contrapartes que preservan el uso de la lengua indígena. En síntesis, en una sociedad hostil al uso de las lenguas indígenas, en la medida en que una persona se encuentre más alejada de la condición lingüística indígena, mayor será su probabilidad de alcanzar una mejor posición económica.

Por su parte, la autoadscripción étnico-racial, y en particular la blanca o mestiza, tiene un efecto menor que el observado para la dimensión lingüística, pero de mayor magnitud que el asociado al tono de piel. Con respecto a la autoadscripción, vale la pena destacar algunos estudios recientes en América Latina (Farah Schwartzman, 2007; Villarreal, 2014; Villarreal y Bailey, 2019) y Estados Unidos (Saperstein y Penner, 2012) que han presentado evidencia de causalidad inversa entre la autoadscripción étnico-racial y la 
posición socioeconómica. ${ }^{8}$ Estos trabajos parten del supuesto (compartido por nosotros) de que la adscripción étnico-racial es una construcción social y por tanto susceptible de cambiar en determinadas circunstancias sociales e históricas (Cornell y Hartmann, 1998). Aunque este fenómeno no es la discusión central de nuestro trabajo y tendría que ser explorado con mayor detalle utilizando datos longitudinales o etnográficos, vale la pena considerar que si en efecto se da el tránsito o reposicionamiento individual (Wimmer, 2008) entre categorías de autoadscripción (de indígena a mestizo, por ejemplo) en función de las condiciones económicas, ello refuerza el argumento de que existen jerarquías étnico-raciales socialmente compartidas y que dichas estrategias de reposicionamiento individual contribuyen a reforzarlas.

El segundo conjunto de preguntas tiene que ver con la asociación entre las características étnico-raciales y las circunstancias socioeconómicas de origen, tanto familiares como geográficas. En la discusión al inicio del trabajo señalamos que, más que ser dos ejes independientes de la estratificación social, las circunstancias étnico-raciales y socioeconómicas se encuentran históricamente ligadas entre sí por la acumulación de desventajas socioeconómicas asociada al racismo y la discriminación étnico-racial en generaciones previas. También mostramos, al analizar la Gráfica 2, que esto se manifiesta empíricamente en la propensión que tienen las personas con características étnico-raciales vinculadas a la pertenencia a pueblos indígenas o afromexicanos a provenir de familias con un nivel socioeconómico más bajo.

No es sorprendente, por tanto, que al incluir estas características en los modelos de regresión (modelo 5), se reduzcan de forma significativa los efectos de las características étnico-raciales en los destinos económicos. Esto indica que una parte sustantiva de la desigualdad de oportunidades económicas asociada a las características étnico-raciales se explica por la acumulación histórica de las desventajas en las generaciones previas. Debido a esta acumulación originaria de carencias, no es necesario que las personas pertenecientes a pueblos indígenas, hablantes de lengua indígena o con piel morena sean víctimas del racismo y la discriminación en el presente para encontrarse en desventaja, pues "heredan" las desventajas históricas a través de una mayor propensión a nacer y crecer en familias y entornos geográficos con carencias sociales.

Por otra parte, el hecho de que, incluso una vez controladas las circunstancias socioeconómicas de origen, persistan los efectos de las caracterís-

\footnotetext{
${ }^{8}$ Por ejemplo, en el caso examinado aquí, un fenómeno de este tipo se presentaría cuando las personas con algunas características asociadas a lo socialmente construido como "indígena" o que en un momento previo del tiempo se hayan adscrito como indígenas, "cambian" de autoadscripción étnico-racial como resultado de experimentar movilidad social ascendente.
} 
ticas étnico-raciales, sugiere que no toda la desigualdad de oportunidades económicas es explicada por la acumulación de desventajas en generaciones previas, sino que existe un componente de racismo y discriminación persistente en las generaciones actuales que se suma a las desventajas heredadas del pasado. Para dimensionar este problema es necesario estudiar las prácticas de discriminación étnico-racial. En un trabajo reciente (Solís, Krozer, Arroyo Batista y Güémez Graniel, 2019) hemos realizado una taxonomía de estas prácticas a partir de testimonios cualitativos recabados en grupos de enfoque y entrevistas a profundidad realizados en distintas regiones del país. Los resultados revelan que estas prácticas son frecuentes en ámbitos ligados a las oportunidades económicas y en particular en el mundo del trabajo, en donde el acceso y la movilidad interna son frecuentemente condicionados en función de aspectos como el tono de piel o la pertenencia a pueblos indígenas.

En síntesis, nuestros resultados indican que la desigualdad de oportunidades económicas asociada a las características étnico-raciales en México se explica por una combinación de acumulación histórica de desventajas y persistencia de prácticas de racismo y discriminación en el presente. Esto tiene una importante implicación en términos de políticas públicas: para combatir de manera efectiva la desigualdad étnico-racial es necesario desarrollar acciones de política en dos frentes. Primero, políticas de acción afirmativa que compensen por las injusticias y la acumulación de desventajas del pasado, con el objetivo de revertir las "desventajas de cuna" que sufren quienes poseen características étnico-raciales afines a los pueblos indígenas y afrodescendientes. Segundo, políticas antirracistas y antidiscriminatorias más efectivas, que prevengan y combatan la persistencia de prácticas de maltrato persistentes que impiden u obstaculizan el acceso a oportunidades y derechos.

Otra pregunta que hemos planteado al inicio del trabajo es cuál es el papel mediador de la escolaridad en la asociación entre las características étnico-raciales y los destinos económicos. En primer lugar, encontramos que, en consonancia con la literatura sobre desigualdad de oportunidades y movilidad social intergeneracional, la escolaridad está fuertemente asociada a la posición percentílica que ocupan las personas en la distribución económica. En segundo, reportamos que los años de escolaridad están asociados tanto al resto de las características étnico-raciales como a los orígenes sociales, lo que refleja su papel de variable mediadora. Es decir, una fracción significativa del efecto del IOS y de las características étnico-raciales se expresa a través de la desigualdad de oportunidades educativas. Sin embargo, estos efectos no son completamente atribuibles a la inequidad de 
años de escolaridad, pues conservan significancia estadística en el modelo completo (modelo 6).

Por tanto, aunque la reducción de la desigualdad en las oportunidades educativas es primordial para aminorar la desigualdad económica, no es suficiente para neutralizar por completo los efectos de las características étnico-raciales. Es probable que esto se deba en parte a que las brechas en años de escolaridad no resumen apropiadamente la desigualdad educativa: tendrían que ser consideradas también las diferencias en aprendizajes y credenciales de las escuelas a las que se asiste. No obstante, como señalamos, las prácticas discriminatorias no se restringen al ámbito educativo, por lo que, incluso con un acceso equitativo a la educación, es previsible que persista cierta desigualdad asociada a las características étnico-raciales.

Por último, en cuanto a la pregunta sobre desigualdades de género en la asociación de características étnico-raciales y destinos económicos, en este análisis no encontramos diferencias de magnitud considerable en los resultados de modelos para hombres y para mujeres. Una posible explicación es que para el cálculo del IAE se toman datos recolectados a nivel vivienda, lo que no detecta las aportaciones individuales y, por lo tanto, las inequidades económicas según género en el interior de las viviendas. Sería importante, por tanto, replicar en estudios futuros este análisis de diferencias de género, considerando otros indicadores de logro económico, así como indicadores alternativos de logros educativo y ocupacional.

\section{Anexo 1}

Pregunta 10.2 del cuestionario del Módulo de Movilidad Social Intergeneracional 2016

10.2. A partir de la siguiente escala de color (mostrar escala cromática), ¿cuál considera que es el color de piel de su cara?

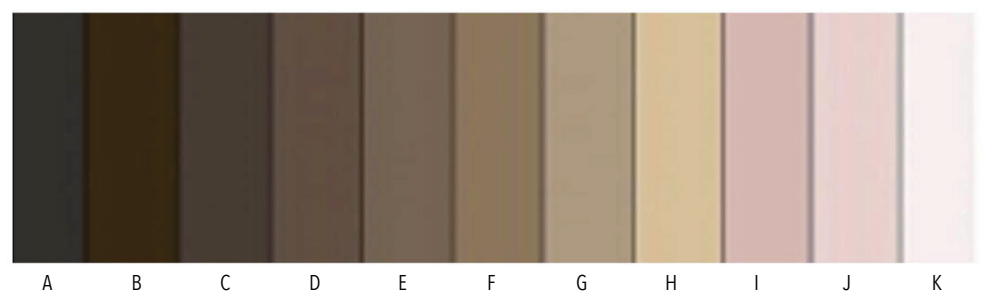

Fuente: Módulo de Movilidad Social Intergeneracional, Encuesta Nacional de los Hogares $(\mathrm{ENH})$ 2016, INEGI. 


\section{Bibliografía}

Aguilar, R. (2011). Social and political consequences of stereotypes. Related to racial phenotypes in Mexico. (Documento de trabajo, núm. 230). Ciudad de México: Centro de Investigación y Docencia Económicas. Recuperado de http://libreriacide.com/librospdf/DTEP-230.pdf

Alkire, S. y Santos, M. E. (2010). Acute multidimensional poverty: A new index for developing countries. (Documento de trabajo, núm. 38). University of Oxford: OPHI. Recuperado de https://ophi.org.uk/acutemultidimensional-poverty-a-new-index-for-developing-countries/

Arceo-Gomez, E. O. y Campos-Vazquez, R. M. (2014). Race and marriage in the labor market: A discrimination correspondence study in a developing. American Economic Review, 104(5), 376-380. Recuperado de https://www.aeaweb.org/articles?id=10.1257/aer.104.5.376

Barbary, O. (2015). Social inequalities and indigenous populations in Mexico: A plural approach. En P. Simon, V. Piché y A. Gagnon (eds.), Social statistics and ethnic diversity. Cross-national perspectives in classifcations and identity politics (pp. 209-228). Cham: Springer. Recuperado de https://link.springer.com/book/10.1007\%2F978-3-319-20095-8

Blau, P. y Duncan, O. D. (1967). The American occupational structure. Nueva York: John Wiley and Sons.

Bonilla-Silva, E. (1997). Rethinking racism: Toward a structural interpretation. American Sociological Review, 62(3), 465-480. Recuperado de https://www.jstor.org/stable/2657316? origin=crossref\&seq=1

Breen, R. y Jonsson, J. O. (2005). Inequality of opportunity in comparative perspective: Recent research on educational attainment and social mobility. Annual Review of Sociology, 31(1), 223-243. Recuperado de https://www.annualreviews.org/doi/10.1146/annurev.soc.31.041304. 122232

Breen, R. y Rottman, D. (1995). Class analysis and class theory. Sociology, 29(3), 453-473. Recuperado de https://journals.sagepub.com/doi/ abs/10.1177/0038038595029003005

Brubaker, R. (2009). Ethnicity, race, and nationalism. Annual Review of Sociology, 35, 21-42. Recuperado de https://www.annualreviews.org/ doi/10.1146/annurev-soc-070308-115916

Bukodi, E. y Goldthorpe, J. H. (2016). Educational attainment -relative or absolute- as a mediator of intergenerational class mobility in Britain. Research in Social Stratification and Mobility, 43, 5-15. Recuperado de https://www.sciencedirect.com/science/article/pii/S027656241 5000049?via\%3Dihub 
Campos-Vazquez, R. M. y Medina-Cortina, E. M. (2019). Skin color and social mobility: Evidence from Mexico. Demography, 56(1), 321-343. Recuperado de https://link.springer.com/article/10.1007/s13524-0180734-Z

Casas Martínez, R., Saldívar, E., Flores, R. y Sue, C. (2014). The different faces of mestizaje: Ethnicity and race in Mexico. En E. E. Telles (eds.), Pigmentocracies. Ethnicity, race, and color in Latin America (pp. 3680). Chapel Hill: The University of North Carolina Press.

Collins, P. (2015). Intersectionality's definitional dilemmas. Annual Review of Sociology, 41, 1-20. Recuperado de https://www.annualreviews.org/ doi/10.1146/annurev-soc-073014-112142

Conapo. (1994). Índice de marginación. Ciudad de México: Consejo Nacional de Población.

Cornell, S. y Hartmann, D. (1998). A constructionist approach. En S. E. Cornell y D. Hartmann (eds.), Ethnicity and race. Making identities in a changing world. Thousand Oaks: Pine Forge Press.

Cortés, F. y Escobar Latapí, A. (2005). Movilidad social intergeneracional en el México urbano. Revista de la CEPAL, 85, 149-167. Recuperado de https://repositorio.cepal.org/bitstream/handle/11362/11005/085149 167_es.pdf? sequence $=1$ yisAllowed $=\mathrm{y}$

Crenshaw, K. (1989). Demarginalizing the intersection of race and sex: A black feminist critique of antidiscrimination doctrine, feminist theory and antiracist politics. The University of Chicago Legal Forum, 1989(1), 139-168. Recuperado de https://chicagounbound.uchicago. edu/cgi/viewcontent.cgi? article $=1052 \&$ context $=$ uclf

Delajara, M. y Graña, D. (2017). Intergenerational social mobility in Mexico and its regions. (Documento de trabajo, núm. 6). México: CEEY. Recuperado de https://ceey.org.mx/wp-content/uploads/2018/06/06-DelajaraGraña-2017.pdf

Dixon, A. R. y Telles, E. E. (2017). Skin color and colorism: Global research, concepts, and measurement. Annual Review of Sociology, 43, 405-424. Recuperado de https://www.annualreviews.org/doi/10.1146/ annurev-soc-060116-053315

Farah Schwartzman, L. (2007). Does money whiten? Intergenerational changes in racial classification in Brazil. American Sociological Review, 72(6), 940-963. Recuperado de https://www.jstor.org/stable/ 25472504? seq $=1$

Feagin, J. y Elias, S. (2013). Rethinking racial formation theory: A systemic racism critique. Ethnic and Racial Studies, 36(6), 931-960. Recupera- 
do de https://www.tandfonline.com/doi/abs/10.1080/01419870.2012.6 69839

Filmer, D. y Pritchett, L. (2011). Estimating wealth effects without expenditure data-or tears: An application to educational enrollments in states of India. Demography, 38(1), 115-132. Recuperado de https://pubmed. ncbi.nlm.nih.gov/11227840/

Flores, R. y Telles, E. (2012). Social stratification in Mexico: Disentangling color, ethnicity, and class. American Sociological Review, 77(3), 486-494. Recuperado de https://journals.sagepub.com/ doi/10.1177/0003122412444720

Fox, L., Torche, F. y Waldfogel, J. (2017). Intergenerational mobility. En D. Brady y L. Burton (eds.), The Oxford handbook of social science of poverty. Volume 1 (pp. 258-554). Oxford: Oxford University Press. Recuperado de https://www.oxfordhandbooks.com/view/10.1093/oxfordhb/ 9780199914050.001.0001/oxfordhb-9780199914050-e-24

Ganzeboom, H. y Treiman, D. (1996). Internationally comparable measures of occupational status for the 1988 International Standard Classification of Occupations. Social Science Research, 25(3), 201-239. Recuperado de https:/www.sciencedirect.com/science/article/abs/pii/ S0049089X96900101?via\%3Dihub

Goldthorpe, J. H. y Jackson, M. (2008). Education-based meritocracy: The barriers to its realization. En A. Lareau y D. Conley (eds.), Social class. How does It work? (pp. 93-117). Nueva York: Russell Sage Foundation.

González de Alba, I. G. (2017). Poverty, remoteness and social mobility of the indigenous population in Mexico. (Tesis de doctorado en Estudios de Desarrollo, Universidad de Oxford). Recuperado de https:// ora.ox.ac.uk/objects/uuid:1dbfdd83-359a-4c0b-bad3-84ea9b5b61fe/ download_file?file_format $=$ pdf\&safe_filename=ThesisIGGAFinal. pdf\&type_of_work=Thesis

INEGI. (2016). Módulo de Movilidad Social Intergeneracional (MMSI) 2016. Aguascalientes, México: Instituto Nacional de Estadística y Geografía. Recuperado de https://www.inegi.org.mx/programas/mmsi/ $2016 /$

INEGI. (2017). Encuesta Nacional de los Hogares (ENH) 2017. Aguascalientes, México: Instituto Nacional de Estadística y Geografía. Recuperado de https://www.inegi.org.mx/programas/enh/2017/default.html\# Herramientas

Kolenikov, S. y Angeles, G. (2004). The use of discrete data in PCA: Theory, simulations, and applications to socioeconomic indices. (Documento de trabajo, WP-04-85). Chapel Hill: University of North Carolina, Caroli- 
na Population Center. Recuperado de https://www.measureevaluation. org/resources/publications/wp-04-85

Loveman, M. (1999). Is race essential? American Sociological Review, 64(6), 891-898. Recuperado de https://psycnet.apa.org/record/ 2000-13386-007

Monroy-Gómez-Franco, L., Vélez-Grajales, R. y Yalonetzky, G. (2018). Layers of inequality: Social mobility, inequality of opportunity and skin colour in Mexico. (Documento de trabajo, núm. 3). Ciudad de México: Centro de Estudios Espinosa Yglesias. Recuperado de https://ceey.org. $\mathrm{mx} /$ wp-content/uploads/2018/12/03-MGF-Velez-Yalonetzky-2018.pdf

Navarrete Linares, F. (2016). México racista: una denuncia. Ciudad de México: Penguin Random House.

Nutini, H. G. (1997). Class and ethnicity in Mexico: Somatic and racial considerations. Ethnology, 36(3), 227-238. Recuperado de https:// www.jstor.org/stable/3773987?seq=1

Ramírez, A. (2005). México. En G. Hall y H. A. Patrinos (eds.), Indigenous people, poverty and human development in Latin America, 1994-2004 (pp. 150-198). Londres: Palgrave Macmillan.

Roth, W. D. (2016). The multiple dimensions of race. Ethnic and Racial Studies, 39(8), 1310-1338. Recuperado de https://www.tandfonline. com/doi/full/10.1080/01419870.2016.1140793

Saperstein, A. y Penner, A. M. (2012). Racial fluidity and inequality in the United States. American Journal of Sociology, 118(3), 676-727. Recuperado de https://www.jstor.org/stable/10.1086/667722?seq=1

Serrano Espinosa, J. y Torche, F. (eds.). (2010). Movilidad social en México. Población, desarrollo y crecimiento. Ciudad de México: Centro de Estudios Espinosa Yglesias.

Shavit, Y. y Park, H. (2016). Introduction to the special issue: Education as a positional good. Research in Social Stratification and Mobility, 43, 1-3. Recuperado de https://www.sciencedirect.com/science/article/pii/ S0276562416000032?via\%3Dihub

Solís, P. (2007). Inequidad y movilidad social en Monterrey. Ciudad de México: El Colegio de México, A.C.

Solís, P. (2018). Barreras estructurales a la movilidad social intergeneracional en México. Un enfoque multidimensional. (Documento de trabajo, núm. 176). Ciudad de México: CEPAL (Estudios y Perspectivas). Recuperado de https://repositorio.cepal.org/bitstream/handle/113 62/43768/1/S1800693_es.pdf 
Solís, P. y Boado, M. (2016). Y sin embargo se mueve. Estratificación social y movilidad intergeneracional de clase en América Latina. Ciudad de México: Centro de Estudios Espinosa Yglesias.

Solís, P. y Dalle, P. (2019). La pesada mochila del origen de clase. Escolaridad y movilidad intergeneracional de clase en Argentina, Chile y México. Revista Internacional de Sociología, 77(1), 1-17. Recuperado de http://revintsociologia.revistas.csic.es/index.php/revintsociologia/ article/view/1018

Solís, P., Krozer, A., Arroyo Batista, C. y Güémez Graniel, B. (2019). Discriminación étnico-racial en México: una taxonomía de las prácticas. En J. Rodríguez Zepeda y T. González Luna Corvera (coords.), La métrica de lo intangible: del concepto a la medición de la discriminación (pp. 55-94). Ciudad de México: Consejo Nacional para Prevenir la Discriminación.

Telles, E. (2004). Race in another America: The significance of skin color in Brazil. Nueva Jersey: Princeton University Press.

Telles, E. (2014). Pigmentocracies. Ethnicity, race, and color in Latin America. Chapel Hill: The University of North Carolina Press.

Telles, E., Flores, R. y Urrea-Giraldo, F. (2015). Pigmentocracies: Educational inequality, skin color and census ethnoracial identification in eight Latin American countries. Research in Social Stratification and Mobility, 40, 39-58. Recuperado de https://www.sciencedirect.com/ science/article/pii/S0276562415000177?via\%3Dihub

Telles, E. y Torche, F. (2018). Varieties of indigeneity in the Americas. Social Forces, 97(4), 1543-1570. Recuperado de https://academic.oup. com/sf/article-abstract/97/4/1543/5113163?redirectedFrom=fulltext

Tilly, C. (1999). Durable inequality. Berkeley: University of California Press.

Torche, F. (2014). Movilidad intergeneracional y desigualdad: el caso latinoamericano. Annual Review of Sociology, 40(1), 1-25. Recuperado de https://www.annualreviews.org/doi/pdf/10.1146/annurevsoc-062215-092006

Trejo, G. y Altamirano, M. (2016). The Mexican color hierarchy. How race and skin tone still define life chances 200 years after independence. En J. Hooker y A. B. Tillery (eds.), The double bind: The politics of racial and class inequalities in the Americas (pp. 1-14). Washington, DC: American Political Science Association.

Viáfara López, C. A. y Urrea Giraldo, F. (2006). Efectos de la raza y el género en el logro educativo y estatus socio-ocupacional para tres ciudades colombianas. Desarrollo y Sociedad, 58, 115-163. Recuperado de https://revistas.uniandes.edu.co/doi/pdf/10.13043/dys.58.4 
Villarreal, A. (2010). Stratification by skin color in contemporary Mexico. American Sociological Review, 75(5), 652-678. Recuperado de https:// journals.sagepub.com/doi/10.1177/0003122410378232

Villarreal, A. (2014). Ethnic identification and its consequences for measuring inequality in Mexico. American Sociological Review, 79(4), 775806. Recuperado de https://journals.sagepub.com/doi/10.1177/00031 22414541960

Villarreal, A. y Bailey, S. (2019). The endogeneity of race: Black racial identification and men's earnings in Mexico. Social Forces, 98(4), 17441772. Recuperado de https://academic.oup.com/sf/article-abstract/98/4/ 1744/5530574?redirectedFrom=fulltext

Wade, P., Urrea-Giraldo, F. y Viveros Vigoya, M. (2008). Raza, etnicidad y sexualidades. Ciudadanía y multiculturalismo. Bogotá, Colombia: Universidad Nacional de Colombia, Centro de Estudios Sociales.

Wimmer, A. (2008). The making and unmaking of ethnic boundaries: A multilevel process theory. American Journal of Sociology, 113(4), 9701022. Recuperado de http://www.columbia.edu/ aw2951/Wimmer MakingUnmaking.pdf

\section{Acerca de los autores}

Patricio Solís tiene doctorado en Sociología por la Universidad de Texas en Austin, maestría en Población por la Facultad Latinoamericana de Ciencias Sociales (Flacso), sede México, y licenciatura en Sociología por la Universidad Autónoma de Nuevo León. Desde 2004 es profesor-investigador en el Centro de Estudios Sociológicos de El Colegio de México, A.C., institución donde también dirigió la revista Estudios Sociológicos (2015-2020). Pertenece al Sistema Nacional de Investigadores. Sus intereses de investigación son: la desigualdad social, la movilidad social, los procesos de reproducción intergeneracional de la desigualdad y la generación de desigualdades sociales a lo largo del curso de vida, con énfasis en las trayectorias educativas y laborales. ORCID: https://orcid.org/0000-0002-9470-8362

Entre sus trabajos más recientes se encuentran:

Solís, P. y Dalle, P. (2019). La pesada mochila del origen de clase. Escolaridad y movilidad intergeneracional de clase en Argentina, Chile y México. Revista Internacional de Sociología, 77(1), 1-17. Recuperado de http://revintsociologia.revistas.csic.es/index.php/revintsociologia/ article/view/1018 
Solís, P., Krozer, A., Arroyo, C. y Güémez, B. (2019). Discriminación étnico-racial en México. Una taxonomía de las prácticas. En J. Rodríguez Zepeda y T. González Luna (eds.), La métrica de lo intangible: del concepto a la medición de la discriminación (pp. 55-94). Ciudad de México: Consejo Nacional para Prevenir la Discriminación.

Solís, P. (2019). Desigualdad social en la finalización de la educación secundaria y la progresión a la educación terciaria. Un análisis multinacional a la luz de los casos del sur de Europa y América Latina. Papers. Revista de Sociología, 104(2), 247-278. Recuperado de https://papers. uab.cat/article/view/v104-n2-solis

Braulio Güémez es pasante de la licenciatura en Sociología de la Facultad de Ciencias Políticas y Sociales de la Universidad Nacional Autónoma de México. Actualmente se desempeña como asistente de investigación en el Centro de Estudios Sociológicos de El Colegio de México, A.C., en temas de estratificación étnico-racial y movilidad social intergeneracional. ORCID: https://orcid.org/0000-0001-6774-5013

Recepción: 22 de mayo de 2020. Aceptación: 10 de julio de 2020. 
